\title{
Attitude of Antenatal Patients in Enugu Toward HIV Screening
}

\author{
Hyginus U Ezegwui', Arthur CIkeme ${ }^{\prime}$ and Chika N. Onwasigwe ${ }^{2}$
}

Departments of 'Obstetrics \& Gynaecology and ${ }^{2}$ Community Medicine, University of Nigeria Teaching Hospital, Enugu.

\begin{abstract}
Objective: To assess attitude towards antenatal Human Immuno Deficiency Virus (HIV) screening in Enugu, Nigeria. Method: A self-report questionnaire was administered to two hundred and nine women attending antenatal booking clinics at the University of Nigerian Teaching Hospital, Enugu.

Results: The mean age was 29.7 years. One hundred and sixty three patients $78.0 \%$ were aware of HIV Screenng before booking while $22.0 \%$ were not aware at the time of booking. A total of 123 women $(58.9 \%)$ had previous HIV Screening while the rest $(41.1 \%)$ accepted the screening for the first time. Educational Level has a significant effect on uptake of HIV test $\mathrm{x}^{2}=8.97, \mathrm{p}=0.003 \mathrm{df}=2$ and on the perceived benefit of HIV Screening $\mathrm{x}^{2}=16.6, \mathrm{p}=0.00005 \mathrm{df}$ $=3$ but has no significant effect on the awareness of vertical transmission $x^{2}=0.62, p=0.43, d f=2$. The reason for declining HIV Screening was that AIDS has no known cure, followed by fear of positive result.

Conclusion: The awareness and attitude of Nigeria pregnant women towards HIV Screening and uptake of the test is good. Educational level has a significant effect on the uptake and perceived benefit of the test. Antenatal women should be offered routine voluntary counseling and testing.
\end{abstract}

Key Words: Antenatal, HIV Screening, Nigeria.

\section{Introduction}

Human Immunodeficiency Virus (HIV) and Acquired Immuno Deficiency Syndrome (AIDS) has remained a scourge in the African continent'. Since the advent of drugs that decrease vertical transmission, attempts are being made to identify those patients that are seropositive. These groups of patients are offered antiretroviral therapy. However, due to perceived stigma and fear attached to HIV/AIDS, most people do not readily accept HIV Screening.

University of Nigeria Teaching Hospital, Enugu located in Eastern Nigeria is predominantly occupied by one of the major tribes; the Igbos. Most of the antenatal women are drawn from both the urban and rural communities that surround Enugu Urban. There is no discriminatory policy in our booking clinic. Any woman that presents is booked. The Department of Obstetrics and Gynaecology recently introduced routine named voluntary counseling HIV and Screening for all women that booked in the antenatal clinics. The introduction of any new service requires evaluation including the views of users, to assess its effectiveness ${ }^{2}$. This study is to assess the attitude of Nigerian women towards HIV Screening as well as factors affecting the uptake of the test.

\section{Materials and Method}

An average of one thousand five hundred women deliver in the University of Nigeria Teaching Hospital, Enugu annually. Booking clinics are conducted on Mondays and Fridays. These antenatal booking clinics were used for the present study. Over a five-month period, a total of two hundred and thirty seven patients attended our booking clinics. Self-administered questionnaire were offered to the women at the booking clinic to asses their attitude and awareness of HIV screening. The questionnaire contained sociodemographic data like age, parity, religion, occupation, marital status and educational level. Antenatal women were required to tick yes or no to the following questions. (a) If you were aware of HIV screening would you still have come for booking? (b) Have you been screened for HIV before? (c) Do you support HIV screening of all women? (d) If you have an option will you decline from HIV screening? (e) If you are positive will you like your husband to know? They were also asked about the perceived benefits of HIV screening and reason for declining screening if they would do so.

Those that were properly filled were analyzed using EPI INFO Version 6 statistical software programme. The level of significance was set at $5 \%$ for the statistical analysis.

\section{Result}

Two hundred and nine women completed the questionnaire out of two hundred and thirty seven, giving a response rate of $88.2 \%$. The age range was between 20 and 41 years. The mean age was 29.7 years with standard deviation of 4.6 years. Majority of the

Correspondence: Dr. H. U. Ezegwui, Department of Obstetrics Gynaecology, College of Medicine, University of Nigeria Teaching Hospital Enugu.

E-mail:uzoegwui@yahoo.co.uk 
patients were in their second pregnancy (70 or 33.5\%) followed by those in the third pregnancy $48(23 \%)$. Others were 47 Para 1, 23 Para 4, 5 Para 0,8 Para 5, 1 Para 7 and 1 Para 8 in descending order. One hundred and thirty six of the patients were employed (65.1\%) and thirty-eight were unemployed $(18.2 \%)$. The rest $(16.7 \%)$ were students. Many were married (196 or $93.8 \%$ ), others were single ( 5 or $2.4 \%$ ) widowed ( 5 or $2.4 \%$ ) and divorced ( 3 or $1.4 \%$ ). One hundred and fifteen $(55.0 \%)$ had tertiary education followed by secondary education ( 83 or $39.7 \%$ ), primary education ( 5 or $2.4 \%$ ) and no formal education (6 or $2.9 \%$ ).

Table 1:

Effect of Education Level on uptake of HIV Screening

\begin{tabular}{lrccc}
\hline Educational Level & n & Yes (\%) & No (\%) \\
\hline No formal education & 6 & $6(100.0)$ & $0(0.0)$ \\
Primary education & 5 & $3(60.0)$ & $2(40.0)$ \\
Secondary education & 83 & $76(91.6)$ & $7(8.4)$ \\
Tertiary & 115 & $112(97.4)$ & $3(2.6)$ \\
\hline
\end{tabular}

$X^{2}=8.97, p=0.003, d f=2$.

The effect of educational level in uptake of HIV Screening was significant $\chi^{2}=8.97 \mathrm{p}=0.003 \mathrm{df}=2$. Educated women were more likely to accept HIV test than those less educated. This is depicted in table 1 . When asked about the perceived benefits of HIV Screening, many sixty two $(29.7 \%)$ were aware that HIV Screening and consequent anti-retroviral therapy for those positive will prevent vertical transmission while $58(27.8 \%)$ said that knowing their HIV status is beneficial to them, $50(23 . .9 \%)$ had no idea about the benefit of the screening while $19(9.2 \%)$ said it prevents horizontal transmission to health workers. Others are to know the health of unborn baby (10 or $4.8 \%$ ), to help couple practice safe sex (6 or $2.9 \%$ ), to reduce the number of HIV positive babies born ( 2 or $0.9 \%)$ and to help care for HIV positive women and babies $(2$ or $0.9 \%)$. The level of education has a significant effect on the knowledge of perceived benefit of HIV Screening $\left(\chi^{2}=16.6, p=0.00005 \mathrm{df}=2\right)$ but has no effect on the awareness of vertical transmission $(p=0.43 \mathrm{df}=2$ and $\chi^{2}=0.62$ ).

\section{Table 2:}

\section{Relationship between educational status and the} perception of HIV screening as beneficial.

\begin{tabular}{lrc}
\hline Educational Level & n & $\begin{array}{l}\text { No of those who perceive } \\
\text { screening as beneficial }\end{array}$ \\
\hline No formal education & 6 & $6(100.0)$ \\
Primary education & 5 & $3(60.0)$ \\
Secondary education & 83 & $76(91.6)$ \\
Tertiary & 115 & $112(97.4)$ \\
\hline
\end{tabular}

$X^{2}=16.6, p=0.00005, d f=3$.
Table 3:

Reasons for declining from HIV Screening

\begin{tabular}{lrc}
\hline Reason & n & \% \\
\hline AIDS has no treatment & 17 & 39.5 \\
Fear of positive test & 16 & 37.2 \\
Obnoxious social stigma attached to it & 5 & 11.6 \\
Screening is too costly & 2 & 4.7 \\
I have been screened before & 2 & 4.7 \\
I can't be infected & 1 & 2.3 \\
Total & 43 & $100.0 \%$ \\
\hline
\end{tabular}

One hundred and sixty three patients $(78.0 \%)$ were aware of HIV Screening at the time of booking while only $46(22 \%)$ were not aware at the time of booking. One hundred and ninety-nine $(95.2 \%)$ of those not aware of HIV screening before booking agreed that routine named HIV Screening will not have deterred them from booking while $10(4.8 \%)$ of the patients said they would not have booked if they were aware of the routine named HIV screening. One hundred and twenty three $(58.9 \%)$ of the women were screened before the index pregnancy while $86(41.1 \%)$ accepted the screening for the first time. Those screened before tend to accept screening more readily than others. Most of the women 197 (94.3\%) supported HIV Screening of all pregnant women while $12(5.7 \%)$ did not support it. Only $31(14.8 \%)$ suggested that HIV screening should be limited to only women at risk.

The most prominent reason for declining HIV Screening is that HIV and AIDS have no known cure 17 (39.5\%), followed by fear of positive result $16(37.5 \%)$. The rest is shown in table 3 . In response to the question, whether they will continue antenatal care and deliver in our centre if test is positive, majority $196(93.8 \%)$ agreed to do so while $12(5.7 \%)$ will prefer to deliver where their HIV status is not known. The rest $1(0.5 \%)$ were not sure. Most of the women's partners $181(86.6 \%) \mathrm{knew}$ about the HIV screening and supported it financially while $25(12.0 \%)$ of the spouse were not aware. Many women supported screening their husbands as well 133 $(63.6 \%)$ while $74(35.4 \%)$ declined bringing their husbands for screening. Two women $(1.0 \%)$ do not know whether to bring their husband or not. One hundred and eight six $(89.0 \%)$ want the result of positive test disclosed to them and their husbands while 21 $(10.0 \%)$ preferred positive test result not to be revealed to their partners while $2(1.0 \%)$ were not sure whether it is beneficial to tell their husbands or not.

\section{Discussion}

The uptake of HIV screening test is good among antenatal women in Enugu. Educational level has a significant effect on the uptake of the HIV screening test and the perceived benefit of the HIV test. The main reason for acceptance of HIV test is for foetal concern. This is a questionnaire study administered to women 
unaccompanied by their husband to the antenatal clinic. They answered the question confidentially. The questionnaire was simple and could easily be filled by the respondents. However, some of the questions have options, which the respondents need to tick thereby not allowing the respondents to freely express themselves. The busy antenatal clinic may not have provided enough privacy. Some of the respondents had no formal education and need to be guided.

Education has a significant effect on the uptake of the test. Women with high educational level accept the HIV test easily. This means that more appropriate information dissemination needs to be developed for the less educated [2]. However in similar studies, high educational levels of the women appeared to be related to the refusal of the test ${ }^{3,4}$. Majority of the pregnant women were aware of the HIV testing during pregnancy at our centre before booking. This may have offered them an opportunity to think and discuss the test before booking. This decision to be screened may have been taken at home. Prior knowledge of the test before booking has been found to increase uptake ${ }^{2}$.

AIDS screening awareness need to be mounted for both men and women. This may offer time for women to think about the HIV Screening before and during pregnancy. This will also help men to participate in encouraging their partners to screen. Women that had previous HIV Screening were $58.9 \%$ and readily accepted a repeat HIV test. This is lower than earlier studies of $61.7 \%$ in France ${ }^{5}$. It would seem from this study, that apprehension for positive HIV test might have been dispelled by previous negative HIV result. Education has a significant effect on the knowledge of perceived benefits of HIV testing. The reason for

\section{References}

1. Giaquinto C, Ruga E, Gia comet V, Rampon O, D'elia R. HIV: mother to child transmission current knowledge and on going studies. Int JGynecol Obstet, 1998; 63: 1615.

2. Duffy T.A., Wolfe CDA, Varden C., Kennedy J. Chrystie I. L. Women's knowledge and attitude, and the acceptability of voluntary antenatal HIV testing. Br JObst Gynaecol, 1998; 105: 849854

3. Cartoux M, Msellate P, Meda N, Weffens EA, Mandel B C, Leroy VG, etal. Attitude of pregnant women towards HIV testing in Abidjan, Cot d'Ivorre and Bobo D'oulasso, Burkina Faso. AIDS, 1998; 12 (17): 233744. accepting HIV test in the index pregnancy remains mainly motivated by foetal concerns, as found in this study and other earlier studies ${ }^{5,6}$. In order to help those that had no knowledge of the benefits of the HIV test, health education on benefits of HIV Screening need to be introduced into routine antenatal health education.

$79.4 \%$ of the women supported mandatory screening test for HIV and $20.6 \%$ did not. This is higher than earlier studies [7]. Voluntary counseling and testing should be introduced into the antenatal care. Health education on the benefit of HIV test should be mounted in the communities, electronic media and include in health education during antenatal clinic. Education of the girl child will overall increase uptake of HIV test. The reasons for refusal of HIV Screening were mainly that AIDS has no known cure and fear of positive test. This small number of women that refuse the HIV test will benefit from repeat counseling. Nurses and doctors working at the antenatal clinics need to be trained and retrained on pretest and post-test counseling.

The cost of the screening and confirmatory test will still exclude patient that need HIV test. When the client test positive, the cost of retroviral drugs may exclude the patient that need anti-retroviral drugs. Future research should aim at cheaper and rapid HIV screening test. In conclusion, majorities of the women attending antenatal clinics are aware of routine named HIV Screening. Additionally they are favourably disposed towards routine named HIV Screening. Educational level has a significant effect on the uptake and perceived benefit of the HIV Screening. Antenatal Women should be offered routine voluntary counseling and testing.

4. Donders GG, Desmyter J, Goubau P, Van Assche FA. Attitude towards serological tests for infection during pregnancy. Arch Gynaecol Obstet, 1993;252: 1617

5. Rey D, Moatti J.P, Obadia Y, Rotily M, Dellamonica P, Gillet Jy, Gastaut JA. AIDS Care, 1995; 7 Suppl 1 (5): 3940.

6. Boyd FM, Simpson WM, Hart GJ, John Stone FD, Goldberg DJ. What do pregnant women think about HIV test? A qualitative study. AIDS Care, 1999; 11:219.

7. Meadows J, Catalan J, Gazzard B. HIV antibody testing in the antenatal clinic. The view of the consumers. Midwifery, 1993; 9: 639 . 